\title{
Mixed Methods Use in Project Management Research
}

Roslyn Cameron, School of Management, Curtin Business School, Curtin University, Perth, Western Australia, Australia

Shankar Sankaran, School of Built Environment, University of Technology, Sydney, Ultimo, New South Wales, Australia

Jeffery Scales, School of Built Environment, University of Technology, Sydney, Ultimo, New South Wales, Australia

\section{ABSTRACT}

Mixed methods research is increasingly being used in business and management disciplines, in spite of positivist traditions. The aim of the study is twofold: (1) to examine the types of mixed methods approaches being used, and (2) to determine the quality of the reporting of mixed methods studies published in the field of project management. A retrospective content analysis of articles from three ranked project management journals was undertaken for a sample period of 2004 to 2010. Our findings suggest the field of project management is in need of capacity building in relation to the good reporting of mixed methods studies.

KEYWORDS: mixed methods research; project management; research methods; research designs

Project Management Journal Vol. 46, No. 2, 90-104 (C) 2015 by the Project Management Institute Published online in Wiley Online Library (wileyonlinelibrary.com). DOI: 10.1002/pmj.21484

\section{INTRODUCTION}

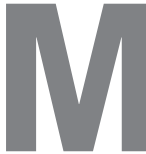
ixed methods research has experienced a growth in popularity over the last decade and has been used to not only provide greater insights into the investigation of research problems but to also address complex phenomena. Mixed methods is being touted as the third methodological movement and is characterized by a growing body of theoretical and methodological frameworks. Prominent mixed methodologists have championed the movement, which has gained strong footholds in the fields of education, health and medicine, and the social and behavioral sciences. The establishment of mixed methods research specific journals, research texts, and its acceptance by research funding bodies indicates a growing trend in the adoption of mixed methods as a legitimate research approach.

One of the main issues and common criticisms of mixed methods is that many who are mixing qualitative and quantitative methods in their research have yet to be acquainted with the growing body of foundational concepts that are developing in the mixed methods research community and as such are not referring, acknowledging, or delving into this growing area of mixed methodology and associated theoretical frames and tools. For example, Leech and Onwugebuzie (2009) point to a "plethora" of mixed methods research designs and typologies available, which now provides researchers with a greater choice in methodological approaches. "For years, the choice has seemed to be dichotomous; one could choose either a quantitative design or a qualitative design. Yet, there is a third viable choice, that of mixed methods. Mixed methods research, which involves combining quantitative and qualitative approaches, is still in its adolescence, and thus, is still relatively unknown and confusing to many researchers" (Leech \& Onwugebuzie, 2009, pp. 265-266). Mertens (2011) notes "Sometimes, authors do not make reference to other literature in the field of mixed methods research, despite the ever-increasing number of resources that are emerging" (p. 3).

Another common criticism of those reporting studies in which qualitative and quantitative methods are being used is that due to a combination of reasons, researchers are only reporting part of their mixed methods studies (usually the quantitative part) so as to increase the probability of being published (because many journals seem to favor papers using quantitative methods) or because of the word limitations associated with the length of journal submissions. Stange, Crabtree, and Miller (2006), editors of the Annals of Family Medicine lament this issue: "the dramatic advances in the scope and sophistication of conducting mixed methods research have not been met with parallel progress in ways of disseminating the results of mixed methods 
studies. From our point of view, a major dilemma is that the results of multimethod studies often are segregated in different publications that reach limited and often nonclinical audiences" (p. 292). Mertens (2011) in attending to her editorial role with the Journal of Mixed Methods Research, refers to these common criticisms in relation to the reporting of mixed methods studies: "Sometimes manuscripts include only quantitative or only qualitative approaches; sometimes they include both quantitative and qualitative approaches, but there is no integration of the methods, analysis, or reporting of findings" (p. 3).

Project management is a rapidly expanding field with its theoretical roots in planning techniques (Koskela \& Howell, 2002; Williams, 2004) which was dominant in the engineering sciences (Söderlund, 2004). In an effort to explore, expand, and inform the field of project management, project management researchers have begun looking at different scientific and management fields. In 2004, for example, the United Kingdom's Engineering and Physical Sciences Research Council (EPSRC) funded a research network-Rethinking Project Management-with the aim of enriching and extending the subject of project management beyond its current conceptual foundations (Winter, Smith, Morris, \& Cicmil, 2006). Bredillet (2007a, b, and c; Anbari, Bredillet, \& Turner, 2008) reviewed the project management academic literature and organized the literature around nine major schools of thought: optimization, modeling, governance, behavior, success, decision, process, marketing, and contingency. More recently, Söderlund (2011) has suggested six schools of project management research: optimization, factor, contingency, behavior, governance, relationship, and decision. He identified growing support for methodological pluralism as project management becomes increasingly viewed from different perspectives and by different scholars.
Several authors have noted the expanding nature of project management research and its evolution over the past two decades (Kwak \& Anbari, 2009; Müller, Sankaran, \& Droiun, 2013; Söderlund, 2004; Turner, Pinto, \& Bredillet, 2011). Söderlund (2004) identified the expansion of project management research into company-wide issues and across various levels of analysis. Turner et al., (2011) refer to the "increasing sophistication and methodological rigour" (p. 103) of project management research as a result of an analysis of the topics, methodologies and citations of project management research published in three project management journals between 1987 and 2007. Kwak and Anbari (2009) studied project management research through allied disciplines as a means to better understanding the field as a researchbased academic discipline. They argue the project management research community needs to actively promote project management as an academic discipline through related management disciplines and concluded that project management is now a more applied and interdisciplinary field compared with other fields of management (Kwak \& Anbari, 2009).

A recently published edited book on novel approaches to organizational project management (OPM) research has the stated aim of improving the rigor of project management research by "open[ing] the minds of project management researchers to the necessity of transforming and translating knowledge from various sources including allied fields into OPM research to raise the level and variety of research approaches that they employed" (Müller et al., 2013, p. 472). Müller et al. (2013), in a discussion on OPM research refer to the:

...trend towards plurality in perspectives, multi-paradigm approaches and the integration of the results from multi-paradigm research in the form of a disciplined search for complementarities, and convergent and divergent results in order to build a holistic understanding of research phenomena (p. 473).
These authors cite several trends in project management research, including: the use of more rigorous methodologies; the increasing breadth of topics; the increase in methodological commentaries; the increase in literature reviews, survey-based research and case studies and; an increase in the publication of qualitative studies. Methodological diversity and variety "nutures the growth in knowledge and understanding in the field" (Müller et al., 2013 p. 24). As has been asserted by Cameron and Sankaran (2013), the use of mixed methods by project management researchers could encourage a move away from traditional methods (surveys, interviews, and case studies) and to the adoption of "more innovative approaches by using mixed methods research designs not just for triangulation as a validation strategy, but also to add more in-depth investigation and a broader perspective of the phenomenon being researched" (p. 398). Frequently using only a small number of methodologies in project research is not desirable to the development of the field itself because it produces inertia and can limit the ability to produce new and interesting research. In addition to the authors cited above, several other project management researchers have recognized this and have proposed the adoption of different lenses from which to view project management problems (Malgrati \& Damiani, 2002; Bredillet, 2004; Cicmil, Williams, Thomas, \& Hodgson, 2006).

This study has taken an exploratory approach to investigating the use and quality of the reporting of mixed methods in recent project management research as represented by a sample of published research in three project management journals from 2004 to 2010. The three chosen journals are the: International Journal of Project Management (IJPM), Project Management Journal $^{\circ}$ (PMJ), and IEEE Transactions on Engineering Management (IEEE-TEM). These three journals were also chosen by Turner, Pinto, and Bredillet (2011) in their study, which was subsequently 
published in the Oxford Handbook of Project Management. They analyzed the project management research reported in these journals from 1997 to 2007 with respect to the topics covered, methodologies employed, and citation patterns. These authors also consulted with project management academic researchers to confirm that this choice was appropriate. The study and its findings identified these three journals as leading the publication of publications research, whereas Kwak and Anbari (2009) refer to IJPM and PMJ as the "flagship" journals of project management research. This study also chose these journals owing to their standing in the field and impact factors $(I J P M=1.758 ; P M J=$ 0.63; IEEE-TEM = 0.94).

The research being reported here has made use of a multistrand conversion mixed model research design, with an overarching research question and separate quantitative and qualitative subquestions. The retrospective content analysis provides a broad-based scan of methodological use, employing collections of separate keywords associated with qualitative and quantitative research methodologies. This resulted in a sample of 214 papers from across the three journals. These articles were then categorized as follows: conceptual (nonempirical); qualitative; quantitative; and mixed methods. This resulted in 25 articles being identified as mixed methods studies. The study then classified the identified mixed methods papers in terms of data collection sequencing, dominance, and analysis. This was followed by a qualitative analysis of the mixed methods papers using a set of quality criteria for the reporting of a mixed methods study developed by Morse and Neihaus (2009) as elaborated on further in this article. Two articles from the 25 were identified as being examples of good quality reporting of mixed methods research (not the quality of the research itself) and are discussed against the evaluative framework for the reporting of mixed methods research. It is hoped that the findings of this study will inform the project management research community about what constitutes good reporting of mixed methods studies and how researchers can use mixed methods in the future to investigate complex phenomena, to utilize innovative methodologies with confidence, and to fully report these studies using not only methodological justification, logic, and rigor but the increasingly sophisticated mix methodology toolkit.

This article will briefly outline the rise of mixed methods as a third methodological movement and discuss mixed methods prevalence rate studies from across business and management disciplines. The purposes or rationales provided for utilizing mixed methods as posited by the mixed methods research community is explained before detailing the aims, research design, methodology, and findings of the study being reported. The findings point to mixed methods remaining rare in the field of project management and to researchers being tentative in their application of the various approaches, choosing largely to keep quantitative and qualitative narratives separate. They are also not describing their reasons for using mixed methods, making it difficult to establish whether their approach to their research questions is consistent with the epistemology underlying the choice of methods.

A key contribution of this study is in evaluating the reporting of mixed methods research in project management by the best practices established and lessons learned in other disciplines that are leading the adoption of mixed methods. We hope to assist new researchers in project management and allied fields to use a mixed methods approach more confidently and with justification, without fear of rejection by editors and reviewers all too familiar with reading project management research outputs developed using conventional methods. The article concludes with recommendations for the future reporting of mixed methods research in the project management field.

\section{Mixed Methods Research: What Is It and How Is It Judged?}

Mixed methods research is an emerging methodology, which has been referred to as the third methodological movement. It is a growing area of methodological choice for many academics and researchers from across a variety of discipline areas. Creswell and Plano Clark (2011) have mapped a brief history of mixed methods and its evolution to date, and have posited five, overlapping, time periods in the evolution of mixed methods. These periods are: formative (1950s-1980s); paradigm debate (1970s-late 1990s); procedural development (late 1980s-2000); advocacy and expansion (2000-2009); and reflective (2003+).

According to Johnson and Onwugebuzie (2004), "Mixed methods research is formally defined here as the class of research where the researcher mixes or combines quantitative and qualitative research techniques, methods, approaches, concepts or language into a single study" (p. 17). Tashakkori and Teddlie (2003) define mixed methods as "a type of research design in which QUAL [qualitative] and QUAN [quantitative] approaches are used in types of questions, research methods, data collection and analysis procedures and/ or inferences" (p. 711). Stange et al. (2006) refer to mixed methods research, which "brings together numbers and narratives, description, hypothesis testing, hypothesis generation, and understanding of meaning and context to provide fuller discernment and greater transportability of the phenomenon under study" (p. 292).

Creswell and Plano Clark (2007) define mixed methods as:

A research design with philosophical assumptions as well as methods of inquiry. As a methodology, it involves philosophical assumptions that guide the direction of the collection and analysis of data and the mixture of qualitative and quantitative data in 
a single study or series of studies. Its central premise is that the use of quantitative and qualitative approaches in combination provides a better understanding of research problems that either approach alone (p. 5).

Thus, mixed methods can be used at any stage of the research and within a single study or in a program of studies. However, both quantitative and qualitative methods have to be used in some combination to qualify as mixed methods research. Mixed methods is different than multimethod research, which is defined as "designs in which the research questions are answered by using two data collection procedures (e.g., participant observation and oral histories) or two research methods (e.g., ethnography and case study), each of which is from the same QUAL or QUAN tradition" (Tashakorri \& Teddlie 2003, p. 11). The distinction between mixed methods and multimethod research is that the former utilizes both qualitative and quantitative data.

Tashakkori and Teddlie (2010) state that mixed methods has:

gone through a relatively rapid growth spurt ... it has acquired a formal methodology that did not exist before and is subscribed to by an emerging community of practitioners and methodologists across the disciplines. In the process of developing a distinct identity, as compared with other major research communities of researchers in the social and human sciences, mixed methods [research] has been adopted as the de facto third alternative, or third methodological movement (pp. 803-804).

\section{Why Has the Mixed Methods Movement Been Gaining Momentum?}

A look at the purposes of using mixed methods will give us some clues to its increasing popularity and utility. Greene (2007) proposes five major purposes for using mixed methods in research studies: triangulation, complementarity, development, initiation, and expansion. Triangulation is a classic technique of using a combination of methods in a study as a validation strategy. The second purpose, complementarity is where different methods are used so as to enable a deeper and richer understanding of a complex research phenomenon. The development purpose for using a mix of methods is related to one method informing another thereby leveraging off the strengths of both methods in the assessment of a set of constructs or phenomena. Using mixed methods to initiate fresh ideas, insights, and perspectives and to look for divergence and dissonance is the fourth purpose and the last is expansion. In the latter case, mixed methods can be used to expand a study in terms of its range and scope.

There have been a handful of evaluative criteria developed to judge the quality of the reporting of mixed methods and these criteria and frameworks shed light on what needs to be reported in a study that has utilized mixed methods. Sale and Brazil (2004) identified criteria for assessing the quality of mixed methods studies to: "promote standards for guiding and assessing the methodological quality of [mixed methods] studies" (p. 361). Their quality criteria identified for mixed methods studies include:

- Truth value (credibility versus internal validity)

- Applicability (transferability/fittingness versus external validity/generalizability)

- Consistency (dependability versus reliability)

- Neutrality (confirmability versus objectivity)

These criteria have been aligned to commonly used criteria found in both quantitative and qualitative quality criteria. An oft cited quality framework for judging the reporting of mixed methods is the Good Reporting of A Mixed Methods Study (GRAMMS) framework. The GRAMMS was developed by O'Cathain, Murphy, and Nicholl (2008) and is a practical and valuable set of quality criteria questions used for reporting mixed methods studies, as follows:

1. Describe the justification for using a mixed methods approach to the research question

2. Describe the design in terms of the purpose, priority, and sequence of methods

3. Describe each method in terms of sampling, data collection, and analysis

4. Describe where integration has occurred, how it has occurred, and who has participated in it

5. Describe any limitation of one method associated with the presence of the other method

6. Describe any insights gained from mixing or integrating methods (p. 92).

The increasing legitimacy and acceptance of mixed methods has seen various research grant awarding bodies, including the U.S. based National Institute of Health (NIH), suggesting guidelines to evaluate mixed methods funding applications (NIH, 2010). They propose applicants refer to several standards for reviewing the quality of the reporting of mixed methods, such as those developed by Creswell and Plano Clark (2011), Schifferdecker and Reed (2009), and the GRAMMS framework.

Morse and Neihaus (2009) developed an evaluative framework for mixed methods studies and this is the framework employed to evaluate the 25 mixed methods articles identified in this study. Morse and Niehaus (2009) developed a "dissection chart" to systematically examine and clarify the design of mixed methods in published articles. They suggest that in order to dissect a article, one will have to start reading the entire article by first making notes, highlighting the aim of the study, examining the research questions that were asked, looking at the sample used for the components of study, noting the methods, and examining the pacing of the data collection and interface points. The 
analysis should then begin using the criteria listed below:

1. Identify:

a. Theoretical drive-investigating whether the researcher approached the study inductively or deductively will allow the reader to determine the theoretical drive.

b. Core component or the primary part of the aim(s) and research questions.

c. Supplemental component or the component that is not complete but supports the core component.

d. Point(s) of interface to note how the data sets were combined and analyzed (separately and then combined or together).

2. Identify the type of mixed methods design (qualitatively driven and quantitatively driven designs).

3. Evaluate the adequacy of the study by answering the following questions:

a. What is the nature of the phenomenon under investigation?

b. Were the QUAL/QUAN methods/ strategies appropriately used? Give reasons.

c. What is the nature of the primary sample? Was it appropriate? Was it adequate?

d. Did the supplementary component of the project require a different sample? If so, was it adequate and appropriate?

e. Consider the generalizability of the study? Has (have) the author(s) over/under generalized? Give reasons.

4. This is followed by an evaluation of the rigor of the study:

a. Can the core component stand alone?

b. Is the supplementary component adequate for the study purposes?

c. What violations to reliability and validity (if any) occurred?

5. Outline the design of each mixed methods article by drawing a flowchart.
The dissection chart described is very thorough and assisted the authors in deciding to use this evaluative framework over the others mentioned above.

\section{Prevalence Rates Studies of Mixed Methods Research in Business and Management Disciplines}

Cameron and Molina-Azorin (2011) investigated the acceptance of mixed methods in business and management research by synthesizing the results of several mixed methods prevalence studies across the following disciplines: marketing, international business, operations management, entrepreneurship, strategic management, and organizational behavior (see Cameron \& Molina-Azorin for details about actual journals used in these studies). All the studies endeavored to discover the extent and the current role mixed methods plays in business/management fields through a process of content analysis of empirical studies published in discipline-based academic journals. Alise and Teddlie (2010) refer to these as prevalence rate studies, which are emerging from within the mixed methods community. The conceptual articles were removed from the analyses to enable a presentation of the results based on the empirical articles (qualitative, quantitative, or mixed methods) identified and summarized in Table 1.

Cameron and Molina-Azorin (2011) identified disciplines where the reporting of mixed methods was minimal (organizational behavior and entrepreneurship), and where it was more prevalent than qualitative research (strategic management, marketing, and international business). They found quantitative methods (76\%) dominated across the disciplines reported for all the studies, with mixed method studies representing $14 \%$ and qualitative studies representing $10 \%$ of all the empirical articles, respectively.

\begin{tabular}{|c|c|c|c|c|}
\hline Discipline & Quant & Qual & Mixed & Total \\
\hline $\begin{array}{l}\text { Marketing } \\
\text { Three journals 1993-2002 } \\
\text { Hanson and Grimmer (2005) }\end{array}$ & $\begin{array}{c}553 \\
(75 \%)\end{array}$ & $\begin{array}{c}78 \\
(11 \%)\end{array}$ & $\begin{array}{c}105 \\
(14 \%)\end{array}$ & $\begin{array}{c}736 \\
(100 \%) \\
(31 \%)\end{array}$ \\
\hline $\begin{array}{l}\text { International business } \\
\text { Four journals 2000-2003 } \\
\text { Hurmerinta-Peltomaki and } \\
\text { Nummela (2006) }\end{array}$ & $\begin{array}{c}269 \\
(68 \%)\end{array}$ & $\begin{array}{c}57 \\
(15 \%)\end{array}$ & $\begin{array}{c}68 \\
(17 \%)\end{array}$ & $\begin{array}{c}394(100 \%) \\
(17 \%)\end{array}$ \\
\hline $\begin{array}{l}\text { Strategic management } \\
\text { One journal 1997-2006 } \\
\text { Molina-Azorin (2009) }\end{array}$ & $\begin{array}{c}441 \\
(78 \%)\end{array}$ & $\begin{array}{c}30 \\
(5 \%)\end{array}$ & $\begin{array}{c}99 \\
(17 \%)\end{array}$ & $\begin{array}{c}570(100 \%) \\
(24 \%)\end{array}$ \\
\hline $\begin{array}{l}\text { Organizational behavior } \\
\text { One journal 2003-2008 } \\
\text { Molina-Azorin and Lopez- Fernandez (2009) }\end{array}$ & $\begin{array}{c}197 \\
(85 \%)\end{array}$ & $\begin{array}{c}17 \\
(7.5 \%)\end{array}$ & $\begin{array}{c}17 \\
(7.5 \%)\end{array}$ & $\begin{array}{c}231(100 \%) \\
(10 \%)\end{array}$ \\
\hline $\begin{array}{l}\text { Operations management } \\
\text { One journal 2003-2007 } \\
\text { Molina-Azorin (2008) }\end{array}$ & $\begin{array}{c}146 \\
(78 \%)\end{array}$ & $\begin{array}{c}23 \\
(12 \%)\end{array}$ & $\begin{array}{c}18 \\
(10 \%)\end{array}$ & $\begin{array}{c}187(100 \%) \\
(8 \%)\end{array}$ \\
\hline $\begin{array}{l}\text { Entrepreneurship } \\
\text { Two journals 2003-2007 } \\
\text { Molina-Azorin (2008) }\end{array}$ & $\begin{array}{c}178 \\
(76 \%)\end{array}$ & $\begin{array}{c}37 \\
(16 \%)\end{array}$ & $\begin{array}{c}20 \\
(8 \%)\end{array}$ & $\begin{array}{c}235 \\
(100 \%) \\
(10 \%)\end{array}$ \\
\hline Total & $\begin{array}{l}1784 \\
(76 \%)\end{array}$ & $\begin{array}{l}242 \\
(10 \%)\end{array}$ & $\begin{array}{c}327 \\
(14 \%)\end{array}$ & $\begin{array}{l}2,353 \\
(100 \%)\end{array}$ \\
\hline
\end{tabular}

Source: Adapted from Cameron and Molina-Azorin (2011, p. 259).

Table 1: Summary of empirical papers identified in mixed methods prevalence studies. 


\section{Research Purpose and Questions}

The aim of this study is twofold: (1) to examine the types of mixed methods approaches being used in project management research and (2) to determine the quality of the reporting of mixed methods studies published in the field of project management. We have chosen to use a mixed methods approach to address these aims, because a single method approach would not provide enough detail and data to allow us to fully explore these two aims. Not only do we want to obtain a sense of the utility of mixed methods across the project management field but we also want to explore the quality of the reporting of these studies. This requires us to collect and merge quantitative and qualitative data to develop a more complete understanding of the issues we are trying to explore. If we return to Greene's (2007) five purposes for using mixed methods, then complementarity would be the purpose assigned to this study. We decided that the use of different methods (both quantitative and qualitative) would enable a deeper and richer understanding of the use and quality of the reporting of the mixed methods studies.

Teddlie and Tashakkori (2009, p. 133) refer to an approach to framing research questions in mixed methods that involves proposing an overarching research question and then expanding on this through sub-questions that are either qualitative or quantitative. This has been the approach taken in this study with the aim of achieving a deeper understanding and, as a result, the following overarching research question and research sub-questions were posited:

\section{Overarching Research Question}

RQ1: What are the use and quality of reporting of mixed methods research in project management research?

\section{Quantitative sub-questions}

RQ2: What is the frequency of use of mixed methods research within project management research?
RQ3: Is the integration of data collection and analysis in project management mixed methods research being reported?

\section{Qualitative sub-questions}

RQ4: Do researchers who use mixed methods in project management research explicitly state a rationale or purpose for undertaking mixed methods?

RQ5: Is the priority and sequencing given to qualitative and quantitative data in mixed methods project management research being reported?

\section{Research Design}

There is a vast array of mixed methods typologies and research designs reported in the literature, which can be bewildering even for the experienced researcher. Tashakkori and Teddlie (2003) developed a four-dimensional typology based on a set of four criteria: number of methods used; number of strands or phases; type of implementation-concurrent, sequential, or conversion; and, stage of integration. One of the research designs from this typology is the multistrand conversion mixed model research design, which has been chosen for this research: "In this type of design multiple approach questions are asked. One type of data is collected and analyzed and is then transformed to another data type (qualitized/quantitized) and analyzed accordingly. Two types of inferences are made on the basis of each set of results and are pulled together at the end to generate meta-inferences ... This design ... can also [be] mixed in the conceptualization stage (e.g., questions) as well as in the inference stage" (Tashakkori \& Teddlie, 2003, p. 689). This design has allowed us to quantitize the qualitative data and enables us to answer both the qualitative and quantitative research sub-questions posited.

Figure 1 provides a visual depiction of the multistrand conversion mixed model research design. In the first strand, qualitative secondary data were utilized and quantitized through answering the quantitative research subquestions. The mixed methods articles identified in the first strand were then also analyzed qualitatively in the second

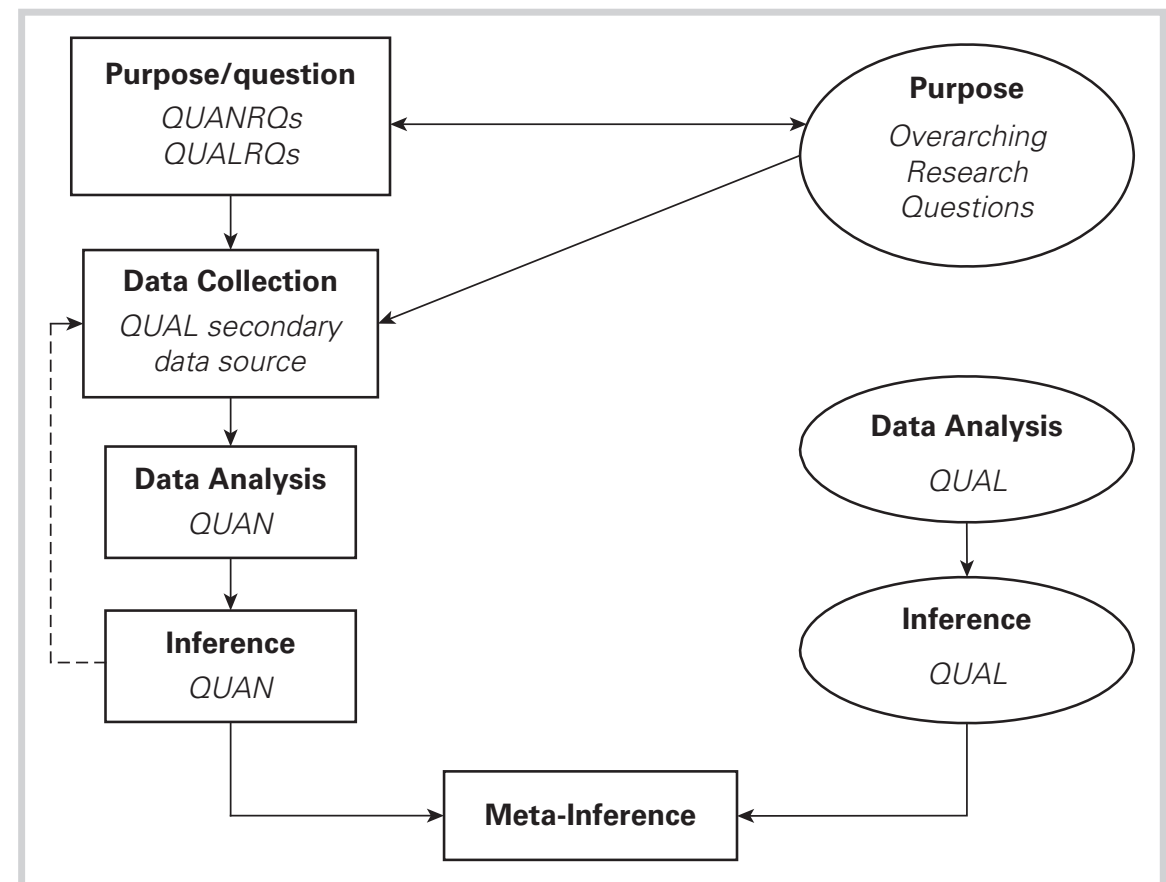

Source: Adapted from Tashakkori and Teddlie (2003, p. 689).

Figure 1: Multistrand conversion mixed model design. 
strand through answering the qualitative research questions focusing on the reviewer's interpretation of the author's reporting of mixed methods justification, sequence, dominance, and so forth. Data were collected and analyzed sequentially, with both the quantitative and qualitative data being of equal importance. Inferences are obtained for both strands of data collection and analysis. A meta-inference is achieved and attends to the overarching research question.

\section{Methodology}

The study conducted a retrospective content analysis of papers published in three select journals prominent in the discipline of project management. The study builds on previous scans of methodological use within the management literature as outlined in Table 1, with a particular focus on articles reporting mixed methods. A retrospective content analysis of articles from three ranked project management journals, selected in consultation with prominent project management scholars, was undertaken. The analysis included four steps: (1) searching 1,755 articles; (2) identifying a sample size of 214 articles that were likely to have used mixed methods; (3) evaluating and selecting 25 articles that met the evaluation criteria used for analysis; and finally, (4) selecting two articles that were considered as having reported the use of mixed methods well based on the criteria applied. The 25 articles have been classified and analyzed in terms of sequencing and dominance of methods and the level of data integration. The three major journals associated with the discipline of project management were chosen based on a previous study undertaken by Turner et al. (2011). The journals selected were the International Journal of Project Management (IJPM), Project Management Journal ${ }^{\circ}$ (PMJ), and IEEE Transactions on Engineering Management (IEEE-TEM). A date range from 2004 to 2010 was chosen to enable electronic searching of publication databases for keywords and to limit the potential sample size. The purpose was not to perform an exhaustive search of all papers published but to look at prominent journals in the discipline over a selected period of time. This study was initiated in 2011, and preliminary results were presented at the EURAM 2012 conference in Rotterdam, Holland. A further study is under way, focusing on the International Journal of Managing Projects in Business, which did not meet the criteria applied for this study having only begun publication in 2008 .

\section{Data Collection}

From the literature reviewed, separate collections of keywords associated with qualitative and quantitative research methodologies were generated. Keyword databases of the chosen journals, which allowed for Boolean coding of search parameters. The electronic search parameters looked for papers containing any one of the qualitative keywords (a Boolean OR function) plus (a Boolean AND function), any one of the quantitative keywords (another Boolean OR function) in the paper's title, abstract, or text body. The premise being that this encapsulates all mixed methods articles that described the use of both a qualitative and a quantitative methodology while also capturing papers that simply referred to such methodologies. Data collection terms were used as evidence of qualitative or quantitative approaches based on their usage in a standard text on business research methods (Bryman \& Bell, 2007).

Searches were structured to result included any of the quantitative terms searches were made using the online in a collection of journal articles, which

as well as any of the qualitative terms. Total search $=(\mathrm{OR}$ of Quantitative terms) AND (OR of Qualitative terms). The actual syntax and process used to achieve this varied, depending on the parameters allowed by the particular database being accessed. The IJPM was accessed through Science Direct; $P M J$ through ProQuest, and the IEEE-TEM through IEEE Xplore. The electronic search parameters yielded an initial sample size of 214 papers, which contained at least one keyword from both the qualitative and quantitative lists from a pool of 1,755 papers published in the three selected journals during the sample period. These 214 papers were then analyzed to determine whether they were in fact mixed methods studies. Strand 1 coding then proceeded to categorize the selected papers using Hurmerinta-Peltomaki and Nummela's (2006) four categories of research articles: conceptual, qualitative, quantitative, and mixed methods. Papers were also coded for their general design type, following Cameron (2009), and for the methods used in generating any empirical data, adapted from Bryman and Bell (2007). This coding process identified 53 papers with the superficial characteristics of a mixed methods approach.

\section{Data Analysis}

Coding focused only on papers identified as potentially mixed methods in Strand 1 and involved applying three mixed methods classification systems. The first was Hurmerinta-Peltomaki and Nummela's (2006) 2 × 2 matrix of data collection/data analysis (Figure 2).

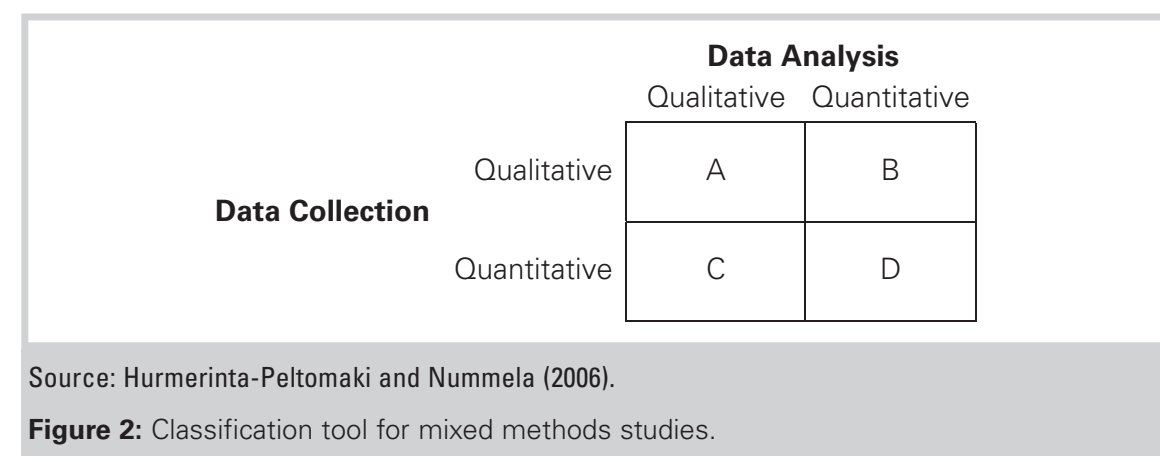


The second was classifications in relation to priority and implementation in mixed methods approaches adapted from Teddlie and Tashakkori (2009). The third was in accordance with Cameron and Molina-Azorin (2010), and included the identification of a stated purpose for utilizing mixed methods and whether the paper was explicit in its use of a mixed methods approach. All three classification systems look at separate dimensions of a mixed methods study.

During each strand of the data analysis at least two reviewers were involved in the coding, which they did separately (R1 and R2). Papers were initially coded by one reviewer (R1) and were then checked by the other (R2), to reduce the impact of reviewer bias. The two reviewers ( $\mathrm{R} 1$ and $\mathrm{R} 2$ ) extracted data from the identified studies using a data collection form with final coding for each paper being discussed during a face-to-face session between the two reviewers (R1 and R2). Disagreements were resolved by discussion; if this was not possible, the third reviewer (R3) adjudicated the discussions (R3).

This coding process identified 53 papers with the superficial characteristics of a mixed methods approach. Strand 2 coding then identified 26 papers, which both reviewers (R1 and R2) agreed showed the necessary characteristics of a mixed methods approach. Finally, when a detailed analysis of the 26 papers using a mixed methods evaluation framework (Morse \& Niehaus, 2009) was carried out, one of the papers was set aside as being a very marginal "B"; therefore 25 papers were included in the final evaluation. For the 25 papers identified, a detailed table was then prepared elaborating how mixed methods were used in each article as per selected results from the three classification systems. A further evaluation of the 25 papers was then carried out using the evaluation criteria suggested by Morse and Niehaus (2009) for analyzing the quality of the reporting of mixed methods, described earlier.
It was not possible to evaluate all the selected papers using the above criteria due to the lack of information in some of the papers. This is an area where the reporting of mixed methods research in project management could be greatly improved through a process of author reflexivity in which the key quality criteria used in evaluating the reporting of mixed methods is applied to their work.

The documents produced from the analysis were as follows:

Excel software was the only software utilized in the data analysis, with an Excel workbook with five sheets describing the approaches used for searching, with two sheets showing the results of the two stages of coding, and a sheet presenting the summary of findings. For each paper that was set aside for further analysis, the following information was recorded in the coding sheet in addition to the bibliographic data:

1. Type of paper: Conceptual/quantitative/qualitative/mixed methods

2. Type of design: Explanatory/exploratory/descriptive/longitudinal/case study/action research/quasi-experimental/experimental/grounded theory/mixed methods/others/unstated

3. Whether the usage of mixed methods is explicitly stated in the paper

4. Whether the purpose or reason for using mixed methods is stated in the paper

5. Whether the dimensions of priority and implementation of the two methods were clarified using the following characteristics:

- Equivalent status and simultaneous or sequential design

- Dominant status and simultaneous and sequential design

6. Mixed methods classification as per Humernita-Peltomaki and Nummela (2006)

7. An initial comment about the paper-for example: Purpose of mixing stated as supplementary confirmation of main approach, in other words, triangulation; simple statistical analysis of quantitative data, no specific analysis of qualitative data, used mainly as explanation/confirmation of quantitative findings

8. Reviewer 1 then recorded conclusions about the paper, for example: States that both QUAN and QUAL data were gathered; a mixed methods paper

9. Reviewer 2 then performed an independent assessment and recorded comments, for example: Not a mixed methods paper, because qualitative data were used only to come up with the research questions

10. The reviewers then met and entered their final conclusions about the paper, For example: Not a mixed methods paper; an example of a paper claiming it is using mixed methods without actually doing so

Table 2 summarizes the results of the evaluation, which allowed the authors to select examples based on the quality of reporting mixed methods. It is to be noted that due to a lack of information provided in the description of the methodology, the intended dominant method in some papers was often not clear and the authors had to use their best judgement to determine this primarily from an analysis of the findings section of the papers. Often the sequencing of the data collection was not apparent or explicitly stated and this was also deciphered through closer reading and discussions between the reviewers.

\section{Discussion}

Our findings point to the fact that, although the use of mixed methods is increasing in project management research, most researchers are not explicitly identifying their studies as mixed methods, as per guidelines we used in evaluating mixed methods research studies in the literature available at the time of the study. We will focus the discussions around the research questions posited based on the journal papers analyzed, followed by some general observations in the 


\begin{tabular}{|c|c|c|c|c|}
\hline & Mixed Methods Description & Type & Paper & Sequence and Dominance \\
\hline 1 & Mixed methods not declared & B & 2 & QUAL $\rightarrow$ QUAN \\
\hline 2 & Mixed methods not declared & $A D$ & 20 & QUAL $\rightarrow$ QUAN \\
\hline 3 & Used term "combined method" & $A D$ & 21 & qual $\rightarrow$ QUAN + qual \\
\hline 4 & Used term "integrated method" & ABD & 29 & QUAN $\rightarrow$ qual \\
\hline 5 & Mixed methods not declared & B & 34 & QUAN $\rightarrow$ QUAL \\
\hline 6 & Mixed methods not declared & $A D$ & 39 & QUAL $\rightarrow$ QUAN $\rightarrow$ qual \\
\hline 7 & Mixed methods not declared & $A D$ & 41 & QUAL $\rightarrow$ QUAN \\
\hline 8 & Mixed methods not declared & $A B$ & 53 & QUAL $\rightarrow$ qual $\rightarrow$ quan \\
\hline 9 & $\begin{array}{l}\text { Mixed methods declared and } \\
\text { rationale provided }\end{array}$ & $A D$ & 59 & QUAL $\rightarrow$ QUAN \\
\hline 10 & Declared MM two stage design & $A C D$ & 69 & QUAN $\rightarrow$ QUAL \\
\hline 11 & Mixed methods not declared & $\mathrm{BD}$ & 71 & QUAN + qual $\rightarrow$ (quan + qual) \\
\hline 12 & Mixed methods not declared & $A B D$ & 72 & QUAL + quan + qual \\
\hline 13 & Mixed methods not declared & $A D$ & 95 & QUAL $\rightarrow$ QUAN $\rightarrow$ qual \\
\hline 14 & Mixed methods not declared & B & 97 & QUAL $\rightarrow$ quan $\rightarrow$ quan \\
\hline 15 & Mixed methods not declared & C & 100 & QUAL $\rightarrow$ QUAN \\
\hline 16 & Mixed methods not declared & B & 106 & QUAL $\rightarrow$ quan \\
\hline 17 & $\begin{array}{l}\text { Split mixed methods study into } \\
\text { two papers (Evaluated paper was } \\
\text { mainly quan) }\end{array}$ & $A C$ & 116 & QUAL + quan \\
\hline 18 & Mixed methods not declared & $A D$ & 126 & QUAL + QUAN \\
\hline 19 & Mixed methods not declared & $A C$ & 130 & qual $\rightarrow$ QUAN $\rightarrow$ qual \\
\hline 20 & Mixed methods not declared & $A B$ & 137 & QUAL $\rightarrow$ qual $\rightarrow$ qual $\rightarrow$ qual $\rightarrow$ quan \\
\hline 21 & $\begin{array}{l}\text { Used the term "triangulated } \\
\text { methods" to describe methodology }\end{array}$ & $A D$ & 168 & qual $\rightarrow$ qual $\rightarrow$ QUAN \\
\hline 22 & Mixed methods not declared & $\mathrm{BD}$ & 185 & QUAN $\rightarrow$ quan $\rightarrow$ QUAL \\
\hline 23 & $\begin{array}{l}\text { Mixed methods not declared } \\
\text { Rationale for two steps given }\end{array}$ & $A B$ & 187 & QUAL $\rightarrow$ QUAN $\rightarrow$ qual \\
\hline 24 & Used term "multilevel" & $A C$ & 188 & QUAL + QUAN $\rightarrow$ qual \\
\hline 25 & Mixed methods not declared & $A D$ & 206 & QUAN + qual \\
\hline
\end{tabular}

Table 2: Results of evaluation.
Molina-Azorin, 2011), where mixed methods articles represented $14 \%$ of all empirical articles reported across the six discipline-based mixed methods prevalence studies. For example, international business and strategic management journals had $17 \%$ mixed methods articles and the lowest rates were for organizational behavior, with $7.5 \%$ rate.

RQ3: Is the integration of data collection and analysis in project management mixed methods research being reported?

Table 4 displays the frequency of usage of a particular mixed methods design in the evaluated papers as per the Humernita-Peltomaki and Nummela (2006) 2 × 2 matrix. This classification system explores the level of data integration being undertaken.

The most frequently found mixed methods approach was $\mathrm{AD}$, in other words, when the data collection and analysis used the same method. The next highest was $\mathrm{B}$, where qualitative data were analyzed using quantitative methods. Three papers used slightly more complex arrangements (ABD and ACD), in other words, where data were analyzed using both methods. There appear to be varying levels of data integration (AC, BD, ABD, and $\mathrm{ACD}$ ) however, the separate treatment of quantitative and qualitative data dominate.

\section{Qualitative sub-questions}

RQ4: Do researchers who use mixed methods in project management research explicitly state a rationale or purpose for undertaking mixed methods?

Generally, this was not done in the conclusion section of this article. We start with the secondary research questions first, before attending to the overarching research question.

\section{Quantitative sub-questions}

RQ2: What is the frequency of use of mixed methods research within project management research?

Table 3 displays the summary of the content analysis of the three journals.
There has been some increase in the percentage of papers reporting the use of mixed methods but the trend is not consistent. The IJPM had the majority of mixed methods papers $(\mathrm{n}=18)$. Overall, only $1.5 \%$ of the sample articles could be found to be using mixed methods over the period sampled. This is low compared with what was found in management journals in earlier research, as depicted in Table 1 (Cameron \& papers; however, we found one paper, which stated it used mixed methods only to find that it did not. Some other terms were used to indicate the use of mixed methods such as "combined," "integrated," and "multilevel" as shown in Table 2. It may be that these researchers have not been exposed to mixed methods and/or have very little experience with mixing methods. In some respects, this may be explained by the 


\begin{tabular}{|l|c|c|c|c|c|c|c|c|c|}
\hline Journal & Year & $\mathbf{2 0 0 4}$ & $\mathbf{2 0 0 5}$ & $\mathbf{2 0 0 6}$ & $\mathbf{2 0 0 7}$ & $\mathbf{2 0 0 8}$ & $\mathbf{2 0 0 9}$ & $\mathbf{2 0 1 0}$ & Total \\
\hline IJPM Total & Total & 95 & 87 & 91 & 99 & 98 & 92 & 92 & 654 \\
& $\mathrm{MM}$ & 2 & 3 & 2 & 3 & 4 & 3 & 1 & 18 \\
\hline \multirow{4}{*}{ IEEE-TM } & $\% \mathrm{MM}$ & $2.11 \%$ & $3.45 \%$ & $2.20 \%$ & $3.03 \%$ & $4.08 \%$ & $3.26 \%$ & $1.09 \%$ & $2.75 \%$ \\
& Total & 102 & 94 & 93 & 118 & 101 & 94 & 112 & 714 \\
\hline \multirow{5}{*}{ PMJ } & $\mathrm{MM}$ & 1 & 1 & 1 & 0 & 0 & 0 & 0 & 3 \\
& $\% \mathrm{MM}$ & $0.98 \%$ & $1.06 \%$ & $1.08 \%$ & $0.00 \%$ & $0.00 \%$ & $0.00 \%$ & $0.00 \%$ & $0.42 \%$ \\
\hline \multirow{5}{*}{ Total } & Total & 45 & 46 & 59 & 56 & 62 & 53 & 66 & 387 \\
& $\mathrm{MM}$ & 0 & 1 & 2 & 0 & 0 & 2 & 0 & 5 \\
& $\% \mathrm{MM}$ & $0.00 \%$ & $2.17 \%$ & $3.39 \%$ & $0.00 \%$ & $0.00 \%$ & $3.77 \%$ & $0.00 \%$ & $1.29 \%$ \\
\hline & Total & 242 & 227 & 243 & 273 & 261 & 239 & 270 & 1755 \\
\hline & $\mathrm{MM}$ & 3 & 5 & 5 & 3 & 4 & 5 & 1 & $26 *$ \\
\hline
\end{tabular}

*One mixed methods paper was deemed marginal and no further analysis was undertaken.

Table 3: Percentage of mixed methods papers found in sampled journals.

\begin{tabular}{|c|c|c|}
\hline Code & Description & $\begin{array}{l}\text { Number } \\
\text { of Studies }\end{array}$ \\
\hline B & Qualitative data analyzed quantitatively & 4 \\
\hline C & Quantitative data analyzed qualitatively & 1 \\
\hline$A B$ & Qualitative data analyzed qualitatively and quantitatively & 3 \\
\hline$A C$ & Qualitative and quantitative data, both analyzed qualitatively & 3 \\
\hline$A D$ & $\begin{array}{l}\text { Qualitative data analyzed qualitatively, quantitative data analyzed } \\
\text { quantitatively }\end{array}$ & 9 \\
\hline $\mathrm{BC}$ & $\begin{array}{l}\text { Qualitative data analyzed quantitatively, quantitative data analyzed } \\
\text { qualitatively }\end{array}$ & Nil \\
\hline $\mathrm{BD}$ & Qualitative and quantitative data, both analyzed quantitatively & 2 \\
\hline $\mathrm{CD}$ & Quantitative data analyzed qualitatively and quantitatively & Nil \\
\hline $\mathrm{ABC}$ & $\begin{array}{l}\text { Qualitative and quantitative data, both analyzed qualitatively, qualitative } \\
\text { data also analyzed qualitatively }\end{array}$ & Nil \\
\hline $\mathrm{ABD}$ & $\begin{array}{l}\text { Qualitative and quantitative data, both analyzed quantitatively, qualita- } \\
\text { tive data also analyzed qualitatively }\end{array}$ & 2 \\
\hline ACD & $\begin{array}{l}\text { Qualitative and quantitative data, both analyzed qualitatively, quantita- } \\
\text { tive data also analyzed quantitatively }\end{array}$ & 1 \\
\hline $\mathrm{BCD}$ & $\begin{array}{l}\text { Qualitative and quantitative data, both analyzed quantitatively, quantita- } \\
\text { tive data also analyzed qualitatively }\end{array}$ & Nil \\
\hline$A B C D$ & $\begin{array}{l}\text { Qualitative and quantitative data, both analyzed concurrently with quali- } \\
\text { tative and quantitative research methods }\end{array}$ & Nil \\
\hline Total & & 25 \\
\hline
\end{tabular}

emergent nature of the mixed methods movement. Nonetheless, the growing body of mixed methods literature and resources indicates this cannot continue to be ignored.
RQ5: Are the priority and sequencing given to qualitative and quantitative data collection and data in mixed methods project management research being reported?
The last column in Table 2 depicts the sequences detected and the priority of the data collected. It is important to point out that, because the sequence was not stated clearly in many of the papers (as per the quality conventions of reporting mixed methods), the researchers had to make the best judgment as to the intended priority and sequence of the data collection by thorough and closer reading of the paper. Only four of the 25 papers used a rationale to justify data collection sequencing; the remainder stated the sequence but did not include a rationale.

The researchers found it difficult to identify the dominant method in many of the papers and where there was doubt, both methods were given equal prominence. This is not considered good practice in the guidelines for the good reporting of a mixed methods study. Paper number 137 had a very complex sequence. Paper 116 mentioned a previous paper, which had published the qualitative aspects of the research, providing an example of a paper where the two components of the study had been published separately. This is an interesting issue faced by those who utilize mixed methods in their research. Researchers must decide how to best publish these studies, especially if they are large and complex. Many journals prescribe word limits for manuscripts and it can be difficult to report on a complete mixed methods study given these limitations. Sometimes authors will only submit the quantitative part of the mixed methods study in the hope of increasing their chances of being published, especially if the discipline and/or journal have a strong quantitative tradition and preferences. This is a dilemma many mixed methods researchers face.

\section{Overarching research question}

RQ1: What are the use and quality of reporting of mixed methods research in project management research?

Nine papers were identified as being good examples of reporting mixed 
methods after the Stage 2 coding process and are listed below.

The two papers selected as quality examples of reported mixed methods as per the evaluation criteria are briefly discussed further to provide some guidelines as to the good reporting of a mixed methods study.

\begin{tabular}{|c|l|c|}
\hline 1. & Chai and Xin (2006), IEEE-TEM & $\mathrm{AD}$ \\
2. & Luu, Kim, and Huynh (2008), IJPM & $\mathrm{AD}$ \\
3. & Milosevic and Patanakul (2005), & $\mathrm{AD}$ \\
& IJPM & \\
4. & Morris and Jamieson (2005), PMJ & $\mathrm{AD}$ \\
5. & Müller and Turner (2007), IJPM & $\mathrm{AD}$ \\
6. & Kutsch and Hall (2009), PMJ & $\mathrm{AB}$ \\
7. & Lechler and Cohen (2009), PMJ & $\mathrm{AC}$ \\
8. & Morris, Jamieson, and Shepherd & $\mathrm{BD}$ \\
9. & (2006), IJPM & \\
\hline
\end{tabular}

The first paper, by Milosevic and Patanakul (2005), described an empirical research carried out to investigate whether standardized project management (SPM) may increase the (product) development project success. They justified the use of a three-staged research process as they were investigating a phenomenon about which very little was known-“SPM and Organizational Project Management Maturity Models (OPM) in high velocity industries" (p. 183).

Although the authors declared that they were using a three-staged research approach, they did not identify the study as mixed methods. The first stage involved semi-structured interviews of 12 project managers, document analyses, and observations. This assisted the authors in developing the research hypotheses and informed the design of a questionnaire that was used in several workshops. Multiple, follow-up interviews with five project managers, from five different companies followed. The dominant data collection was quantitative, with the qualitative data used to achieve a deeper understanding of the issues. For example, a t-test carried out of numerical means, followed by an
ANOVA test did not show any significant difference between the two groups of cases studied. However, the content analysis of qualitative data showed otherwise. The paper interweaved the results from both analyses while discussing the managerial implications of the study, thereby integrating the quantitative and qualitative data.

The authors explained how the research was sequential and analyzed:

[We] use a case research methodology as the first step to develop SPM constructs drawn from real-life context and use its results for the subsequent steps of developing and testing hypothesis for the quantitative study (research step 2). To ensure the validity of our findings and to enrich and refine them we implement step 3 , the follow-up case interviews which is again of qualitative nature (p. 183).

In addition, the authors provided a flow chart, which is very similar to the visual flow charts, to depict the stages that typify those utilized by the mixed methods research community.

The second paper, by Lee-Kelley (2006), reported a study of the locus of control and attitudes of those working within virtual teams. The author referred to the study as a two-staged design:

\begin{abstract}
A prior survey of professional workers involved in defence projects tested the effects of locus of control on team member perceptions of role conflict and job satisfaction. The quantitative results were then compared with the findings of a case-study of IT professionals using in-depth interviews to elicit a deeper understanding of issues facing individuals that was initially indicated in the first study (p. 238).
\end{abstract}

Seven hypotheses were derived from the literature and a survey was sent out via the Association of Project Management. The first stage applied bivariate data analysis, and in the second stage the author conducted interviews of 12 participants from a service company to collect data for a case study. The paper demonstrated a sound use of both quantitative and qualitative methods of analysis.

In analyzing the results from the two methods the author states:

Closer examination of the survey and case-study results in relation to the existing literature suggest that internals' enthusiastic approach to their surroundings and problems could be thwarted by their over-positive judgement of their own abilities to bring about improvements (p. 242).

This led the author to suggest that, although self-management is practical and necessary when managing from a distance, regular project status and performance reviews are required to managing virtual project team effectively.

These papers could be used as exemplars of how to justify and design a mixed methods study, along with recommendations suggested in the conclusions of this paper.

\section{Limitations}

This study was limited in scope due to time and budget constraints. Hence, only three recognized journals were chosen and the study was limited to six years (2004-2010). Despite these constraints, we feel that this will provide a representative picture of the use of mixed methods research, because the journals selected were those used in a previous study (Turner et al., 2011). In addition to this, mixed methods has become more popular since 2003, which was the year the seminal Handbook of Mixed Methods in Social and Behavioural Research was first published. There could be management, engineering, construction, or information systems related journals in which project management research may have been reported using mixed methods research. Kwak and Anbari (2009) identified several journals from eight allied discipline groupings in their study on the publication of project management research across related disciplines. 
Identifying such papers would have taken a lot more effort and time and may be a worthwhile endeavor for future research. Another limitation was the sample size. The analysis in this study was focused on the mixed methods papers. A fuller analysis of all empirical studies (quantitative, qualitative, and mixed methods) would have provided a broader methodological scan of the project management research from within the sample. Quality criteria could also be applied to the the single, or mono-method, quantitative, and qualitative research studies as a means of comparison. The paper uses one suggested guide (Morse \& Niehaus, 2009) for evaluating the mixed methods articles scanned. Other guides for evaluating mixed methods research are available, as mentioned in the literature review, and these could also be used to triangulate the findings.

Given the length of time that has elapsed since the data included in this analysis were first recorded, the first two steps in the sampling process have been revisited. This included the database search and the collation of articles meeting the search criteria by year of publication. The results obtained for the period 2004 to 2010 matched those originally recorded, with small variations. The data were then extended to the years 2011 to 2014 . The total articles published per year and the percentage meeting the search criteria were then averaged separately for the original and more recent periods. The IEEETEM averaged 100 articles per annum in both periods and those meeting the search criteria rose from $26 \%$ to $29 \%$. $P M J$ increased from 55 to 70 articles per annum, but the percentage meeting the criteria remained stable at $4 \%$. The IJPM increased from 93 to 127 articles per annum and also increased the percentage, meeting the criteria from $30 \%$ to $39 \%$. Prima facie evidence, perhaps, that the mixing of qualitative and quantitative methods within project management research is a growing phenomenon.
A further limitation stems from the keyword lists used as the basis for the database searches and how these interact with the changing capabilities of the available search engines. There is also the issue of the varied and changing capabilities of the search engines available on the various databases accessed. These capabilities were seen to change, generally for the better, during the analysis period, generating variations in the raw data and requiring manual intervention to maintain consistency. Although we attempted to limit the effects of any personal interpretation of the common uses applied to the keywords by referencing a standard text, including any particular term was, in the end, the choice of the researchers. It is suggested that further research overcoming these limitations could be carried out to provide a more comprehensive picture of the application of mixed methods in project management research.

\section{Conclusions}

The general observations from this study on the reporting of mixed methods research in project management are: the research design is not explicitly identified as mixed methods research; the sequencing of research methods is not explained using the conventions of mixed methods research; some authors use names other than "mixed methods research" to explain their staged data collection sequence; at least two papers defined and applied mixed methods well and seven others partially applied it; and some authors who used mixed methods decided to present their research as two separate papers, with each paper focusing on one set of data.

Our findings indicate that the use of mixed methods in project management research has increased marginally since 2004; however, it is not keeping pace with the use of mixed methods in other fields of management research. Project management research papers do not explicitly acknowledge the use of mixed methods and it was difficult to identify a paper in the study that followed the guidelines for reporting mixed methods research as located in the literature of mixed methodology. This is not surprising, because project management researchers often do not explain their methodological bases in their papers (Smyth \& Morris, 2007, p. 423) and by not doing so fail to give due consideration to "the importance of coherence in ontology, epistemology and methodology in building a valid philosophical basis for the interpretation of study results" (Biedenbach \& Müller, 2011, p. 83).

If authors follow the guidelines or criteria suggested in the mixed methods research literature, such as the one used to evaluate the studies in this paper, their papers will become richer, more rigorous, and more reflexive. We suggest that, as a minimum requirement, authors should explain the theoretical drive for using mixed methods; identify and describe the core and supplemental components and the purpose for mixing the components; state the points of interface; and identify the type of mixed methods design inclusive of diagram or flowchart displaying how the methods were sequenced and which data were given priority or dominance, as per the mixed methods research notation system. Ideally, we would like to see mixed methods research become part of the armamentarium of project management researchers in order to achieve Teddlie and Tashakkori (2009)'s aim of simultaneously addressing confirmatory and exploratory questions, providing stronger inferences and a greater assortment of divergent views. Our findings suggest that the field of project management is in need of capacity building in relation to the good reporting of mixed methods studies and that the study of complex phenomena can benefit from the use of mixed methods approaches in a field needing to break free from a level of methodological inertia and to promote the field as an academic discipline. A recommendation from this study could be aimed at journal editorial boards and 
a proposed proactive stance on journals providing guidance on the reporting of mixed methods studies/submissions.

Mixed methods research designs can aide project management researchers in the investigation of multifaceted phenomena in innovative ways. Project management researchers need to be encouraged to explore methodological approaches that may be less traditional. Mixed methods can assist project management researchers in conducting transdisciplinary studies with researchers in healthcare, education, social research, and organizational research where mixed methods research designs are prevalent (Cameron \& Sankaran, 2013).

\section{References}

Alise, M. A., \& Teddlie, C. (2010). A continuation of the paradigm wars? Prevalence rates of methodological approaches across the social/behavioral sciences. Journal of Mixed Methods Research, 4(2), 103-126.

Anbari, F. T., Bredillet, C. N., \& Turner, J. R. (2008). Perspectives on research in project management. Paper presented in the Best papers proceedings, Academy of Management 2008 meeting [CD], Anaheim, CA: Academy of Management. Biedenbach, T., \& Müller, R. (2011). Paradigms in project management research: Examples from 15 years of IRNOP conferences. International Journal of Managing Projects in Business. 4(1), 82-104. Bredillet, C. N. (2004, July).

Understanding the very nature of project management: A praxiological approach, in Proceedings of Project Management International Research Conference, London, England.

Bredillet, C. N. (2007a). Exploring research in project management-Nine schools of project management research (Part 3). Project Management Journal, 38(4), 2-4.

Bredillet, C. N. (2007b). Exploring research in project management-Nine schools of project management research (Part 4). Project Management Journal, 39(1), 2-6.
Bredillet, C. N. (2007c). Exploring research in project management-Nine schools of project management research (Part 5). Project Management Journal 39(2), 2-4.

Bryman, A., \& Bell, E. (2007). Business research methods. Oxford, England: Oxford University Press.

Cameron, R. (2009). Changing the paradigm-emerging research designs in professional doctoral research in Australia: Commentary and case studies. In P. Miller \& T. Marchant (Eds.), Business, Education and Indigenous Studies (p. 60). Lismore, New South Wales, Australia: SCU Press.

Cameron, R., \& Molina-Azorin, J. F. (2010, July 8-10). The use of mixed methods across seven business and management fields, justice and sustainability in the global economy: 10th International Federation of Scholarly Associations of Management (IFSAM 2010), Paris, France, IFSAM.

Cameron, R., \& Molina-Azorin, J. F. (2011). The acceptance of mixed methods in business and management research. International Journal of Organizational Analysis, 19(3), 256-271.

Cameron, R., \& Sankaran, S. (2013). Mixed methods research design: Well beyond the notion of triangulation. In N. Drouin, R. Müller, \& S. Sankaran (Eds.), Novel approaches to organizational project management research: Translational and transformational, Copenhagen, Denmark: Copenhagen Business School Press.

Chai, K-H., \& Xin, Y. (2006). The application of new product development tools in industry: The case of Singapore. IEEE Transactions on Engineering Management, 53(4), 435-554.

Cicmil, S. Williams, T. Thomas, J., \& Hodgson, D. (2006). Rethinking project management: Researching the actuality of projects. International Journal of Project Management, 24(8), 675-686.

Creswell, J., \& Plano Clark, V. L. (2007). Designing and conducting mixed methods research. Thousand Oaks, CA: Sage.
Creswell, J. W., \& Plano Clark, V. L. (2011). Designing and conducting mixed methods research (2nd ed.). Thousand Oaks, CA: Sage.

Greene, J. (2007). Mixed methods in social inquiry. San Francisco, CA: JosseyBass.

Hanson, D., \& Grimmer, M. (2005). The mix of qualitative and quantitative research in major marketing journals, 1993-2002. European Journal of Marketing, 41(1-2), 58-70.

Hurmerinta-Peltomäki, L., \& Nummela, N. (2006). Mixed methods in international business research: A value-added perspective. Management International Review, 46(4), 439-459.

Johnson, R. B., \& Onwugebuzie, A. (2004). Mixed methods research: A research paradigm whose time has come. Educational Researcher, 33(7), 14.

Koskela, L., \& Howell, G. (2002). The underlying theory of project management is obsolete. In Proceedings of the PMI Research Conference Project Management Institute, Seattle, WA, pp. 293-301.

Kutsch, E., \& Hall, M. (2009). The rational choice of not applying project risk management in information technology projects. Project Management Journal, 40(3), 72-81.

Kwak, Y. H., \& Anbari, F. T. (2009). Analyzing project management research: perspectives from top management journals. International Journal of Project Management, 27(5), 435-446.

Lechler, T. G., \& Cohen, M. (2009). Exploring the role of steering committees in realizing the value from project management. Project Management Journal, 40(10), 42-54.

Lee-Kelley, L. (2006). Locus of control and attitudes to working in virtual teams, International Journal of Project Management, 24(3), 234-243.

Leech, N. L., \& Onwugebuzie, A. J. (2009). A typology of mixed methods research designs. Quality \& Quantity: International Journal of Methodology, 43(2), 265-275. 
Luu, V. T., Kim, A-Y., \& Huynh, T-A. (2008). Improving project performance of large contractors using benchmarking approach, International Journal of Project Management, 26(7), 758-769.

Malgrati, A., \& Damiani, M. (2002).

Rethinking the new project management framework: New epistemology, new insights. Proceedings of the PMI Research Conference Seattle 2002, (pp. 371-380). Project Management Institute: Newtown Square, PA.

Mertens, D. (2011). Publishing mixed methods research. Journal of Mixed Methods Research, 5(1), 3-6.

Milosevic, D., \& Patanakul, P. (2005). Standardized project management may increase development project success. International Journal of Project Management, 23(3), 181-192.

Molina-Azorin, J. F. (2009). Understanding how mixed methods research is undertaken within a specific research community: The case of business studies. International Journal of Multiple Research Approaches, 3(1), 47-57.

Molina-Azorín, J. F. (2008). Mixed methods research in business management: A comparison of the use of mixed methods in three specific areas. Paper presented at the IV Mixed Methods Conference, Cambridge, England.

Molina-Azorin, J. F., \& Lopez-

Fernandez, O. (2009). Mixed methods research in behavioural sciences: $a$ comparison of mixed methods studies in two specific fields. Paper presented at the V Mixed Methods Conference, Harrogate, England.

Morris, P. W. G., \& Jamieson, A. (2005). Moving from corporate strategy to project strategy. Project Management Journal, 36(4), 5-18.

Morris, P. W. G., Jamieson, A., \& Shepherd, M. M. (2006). Research updating the APM knowledge (4th ed.). International Journal of Project Management, 24, 461-473.

Morse, J., \& Niehaus, L. (2009). Mixed method design: Principles and procedures. Walnut Creek, CA: Left Coast Press, Inc.

Müller, R., \& Turner, J. R. (2007).

Matching the project managers "leadership style" to project type. International Journal of Project Management, 25(1), 21-32.

Müller, R., Sankaran, S., \& Droiun, N. (2013). Introduction. In N. Droiun, R. Müller, \& S. Sankaran (Eds.), Novel approaches to organisational project management research, (pp. 19-30). Copenhagen, Denmark: Copenhagen Business School Press.

NIH. (2010). Best practices for mixed methods research in health sciences, [online], Retrieved from http://obssr. od.nih.gov/scientific_areas/methodology/mixed_methods_research/sectio n6.aspx

O'Cathain, A., Murphy, E., \& Nicholl, J. (2008). The quality of mixed methods studies in health services research. Journal of Health Services Research and Policy, 13(2), 92-98.

Sale, J. E. M., \& Brazil, K. (2004). A strategy to identify critical appraisal criteria for primary mixed-method studies. Quality and Quantity, 38(4), 351-365.

Schifferdecker, K., \& Reed, V. (2009). Using mixed methods research in medical education: Basic guidelines for researchers. Medical Education, 43(7), 637-644.

Smyth, H. J., \& Morris, P. W. G., (2007). An epistemological evaluation of research into projects and their management: Methodological issues, International Journal of Project Management, 25(4), 423-436.

Söderlund, J. (2004). Building theories of project management: Past research, questions for the future. International Journal of Project Management, 22(3), 183-191.

Söderlund, J. (2011). Pluralism in project management: Navigating the crossroads of specialization and fragmentation. International Journal of Management Reviews, 13, 153-176.
Stange, K. C., Crabtree, B. F., \& Miller, W. L. (2006). Publishing multimethod research. Annals of Family Medicine, 4(4), 292-294.

Tashakkori, A., \& Teddlie, C. (Eds.). (2003). Handbook of mixed methods in social and behavioural research. Thousand Oaks, CA: Sage.

Tashakkori, A., \& Teddlie, C. (2010). Epilogue: Current developments and emerging trends in integrated research methodology. In A. Tashakkori \& C. Teddlie (Eds.), Sage handbook of mixed methods in social \& behavioral research, (pp. 803-826). Thousand Oaks, CA: Sage. Teddlie, C., \& Tashakkori, A. (2009). Foundations of mixed methods research: Integrating quantitative and qualitative approaches in the social and behavioral sciences. Thousand Oaks, CA: Sage.

Turner, R., Pinto, J. K., \& Bredillet, C. (2011). The evolution of project management research. In Morris, Peter W. G. \& Pinto, Jeffrey K. (Eds.). The Oxford handbook of project management, (pp. 65-106). Oxford, England: Oxford University Press.

Williams T. (2004, July 11-14). Assessing and building on the underlying theory of project management in the light of badly over-run projects. Proceedings of the PMI Research Conference, London, England.

Winter, M., Smith, C., Morris, P., \& Cicmil, S. (2006). Directions for future research in project management: The main findings of a UK government-funded research network. International Journal of Project Management, 24, 638-649.

Roslyn Cameron is a Research Fellow with Curtin Business School and currently Associate Editor of the Electronic Journal of Business Research Methods and on the Editorial Board Member of the International Journal of Multiple Research Approaches. She is Co-convenor of the Australian and New Zealand Academy of Management (ANZAM) Special Interest Group (SIG) for Mixed Methods (MM), which was launched in December 2011. Roslyn has published widely on the use of 


\section{Mixed Methods Use in Project Management Research}

mixed methods across several disciplines and is a strong advocate for developing research capacity in mixed methods among business and management doctoral students and novice and experienced researchers alike. She can be contacted at ros.cameron@curtin.edu.au

\section{Shankar Sankaran is a Professor of}

Organisational Project Management at the University of Technology Sydney. He has published book chapters, journal articles, and presented papers on the use of mixed methods research in business and management. He has successfully supervised doctoral students who have used mixed methods in their research. He also teaches research methods courses at his school. Shankar has contributed to book chapters on mixed methods research with Ros Cameron in two recently published books on project management research, titled Novel Approaches to Organizational Project Management Research: Translational and Transformational and Design, Methods and Practices for Research of Project
Management. He can be contacted at shankar.sankaran@uts.edu.au

Jeffery Scales recently completed a Master of Project Management at the University of Technology, Sydney after a 20-year career as a project manager in IT, media, and finance. $\mathrm{He}$ is currently pursuing research into system dynamics and the modeling pf project management structures, where pragmatic epistemologies and the mixing of research methodologies have practical use. He can be contacted at jeffrey.scales@uts.edu.au 